\title{
Determinants of Chronic Carbon Dioxide Retention and Its Correction in Humans
}

\author{
James B. Skatrud, Jerome A. Dempsey, Praful Bhansali, and Charles Irvin, \\ Departments of Medicine and Preventive Medicine, University of Wisconsin \\ Center for Health Sciences, and Pulmonary Physiology Laboratory, William S. \\ Middleton Memorial Veterans Hospital, Madison, Wisconsin 53705
}

A B S T RACT 17 patients with chronic ventilatory failure (including 14 with chronic obstructive pulmonary disease) were studied to determine the causes of carbon dioxide retention and the chronic effect of medroxyprogesterone acetate on ventilatory drive and acid-base status. Carbon dioxide retention in patients with high mechanical loads occurred concomitantly with a higher than normal inspiratory effort (mouth occlusion pressure) and normal minute ventilation to carbon dioxide production ratio $\left(\dot{\mathrm{VE}} / \mathrm{V} \mathrm{CO}_{2}\right)$; but with shortened inspiratory time $(1.3 \pm 0.1$ vs. $1.8 \pm 3 \mathrm{~s})$, increased breathing frequency ( $17 \pm 1$ vs. $14 \pm 1$ breaths/ min), low tidal volume $(0.57 \pm 0.03$ vs. $0.88 \pm 0.04 \mathrm{~L})$, and high dead space to tidal volume ratio $(0.63 \pm 0.02$ vs. $0.39 \pm 0.07)$. Using a randomized application of treatment and placebo conditions, it was shown that $4 \mathrm{wk}$ of medroxyprogesterone acetate caused significant reductions in $\mathrm{PaCO}_{2}$ (from $51 \pm 1$ to $42 \pm 1 \mathrm{~mm} \mathrm{Hg}$ ) in 10 of 17 patients. This "correction" of $\mathrm{PaCO}_{2}$ in these patients was associated with increases in mouth occlusion pressure (14\%), tidal volume $(11 \%)$, and alveolar ventilation (15\%) compared to placebo, although inspiratory time remained shortened. Arterial and lumbar cerebrospinal fluid $\mathrm{pH}$ was alkaline compared to placebo in patients who "corrected" $\mathrm{PaCO}_{2}$. No change was noted in lung mechanics or core temperature. Common prerequisites for correction of $\mathrm{PaCO}_{2}$ with medroxyprogesterone acetate treatment were the ability to significantly lower $\mathrm{PaCO}_{2}$ upon acute voluntary hyperventilation and to increase tidal volume rather than breathing frequency in response to the drug. We attribute chronic $\mathrm{CO}_{2}$ retention in these patients to alterations in respiratory cycle timing and to a neuromuscular inspiratory effort which is adequate for the level of tissue $\mathrm{CO}_{2}$

This work was presented in part before the Federation of American Societies for Experimental Biology in April 1978, Atlantic City, N. J.

Received for publication 20 November 1978 and in revised form 14 December 1979. production, but inadequate in the presence of mechanical and ventilation-perfusion abnormalities to normalize arterial blood gases.

\section{INTRODUCTION}

Progesterone was first implicated as a ventilatory stimulant when Hasselbalch and Gammeltoft described hyperventilation and a decreased end-tidal $\mathrm{PCO}_{2}$ in women during pregnancy and during the luteal phase of the menstrual cycle $(1,2)$. In normal males, progesterone administration produced sustained hyperventilation and decreased $\mathrm{PaCO}_{2}(3-5)$. Similarly, a synthetic progestin, medroxyprogesterone acetate (MPA), ${ }^{1}$ lowered the $\mathrm{PaCO}_{2} 5 \mathrm{~mm} \mathrm{Hg}$ in normal subjects by a mechanism independent of arterial blood or cerebrospinal fluid (CSF) $[\mathrm{H}+](6)$.

Progestins have been used therapeutically in the obesity-hypoventilation syndrome and chronic mountain polycythemia, producing increased alveolar ventilation and lower $\mathrm{PaCO}_{2}$ in most patients (7-9). Efficacy of treatment in patients with chronic obstructive pulmonary disease (COPD) and chronic $\mathrm{CO}_{2}$ retention have been less consistent $(10,11)$. Lyons described some emphysematous patients who benefited from progesterone, whereas other patients described subjective discomfort due to dyspnea despite improved arterial blood gases (12). Therefore, although the therapeutic efficacy of progestins has been documented in the obesity-hypoventilation syndrome and chronic mountain polycythemia, its usefulness and predicta-

${ }^{1}$ Abbreviations used in this paper: A-a, alveolar-arterial; COPD, chronic obstructive pulmonary disease; CSF, cerebrospinal fluid; DLCO SB , single-breath diffusion capacity; $\mathrm{dp} / \mathrm{dt}$ max, maximum slope of the inspiratory pressure curve; $f$, respiratory frequency; $\mathrm{FEV}_{1}$, forced expiratory volume in $1 \mathrm{~s}$; MPA, medroxyprogesterone acetate; $P_{0.1}$, mouth occlusion pressure at $100 \mathrm{~ms} ; \mathrm{T}_{1}$, inspiratory time; $\dot{\mathrm{V}}_{\mathrm{A}}$, alveolar ventilation; $\dot{\mathrm{V}} \mathrm{CO}_{2}, \mathrm{CO}_{2}$ production (liters per minute); $\dot{\mathrm{V}}$, expired minute ventilation; VHV, voluntary hyperventilation; VT, tidal volume. 
bility of response in patients with moderate to severe COPD and $\mathrm{CO}_{2}$ retention has not been established.

$\mathrm{CO}_{2}$ retention in these patients has been attributed to both abnormal respiratory cycle timing (13) and decreased inspiratory "drive" or effort in response to increased mechanical load and abnormal ventilation/ perfusion relationships. Previous cross-sectional studies have not provided experimental documentation for these alternative explanations. By examining such factors as respiratory cycle timing and inspiratory effort before and during MPA therapy, the present study attempts to characterize the ventilatory response to MPA and to use this response to experimentally assess alternative mechanisms of chronic $\mathrm{CO}_{2}$ retention.

\section{METHODS}

Study population. 17 outpatients, age $42-68$, with stable chronic $\mathrm{CO}_{2}$ retention were studied. Their mean weight was $94 \pm 15 \mathrm{~kg}$ with a range of $70-230 \mathrm{~kg}$. 14 patients had moderate to severe COPD and 2 of these had lobectomies. In an attempt to use the MPA response to assess possible mechanisms of $\mathrm{CO}_{2}$ retention in diseases other than COPD, three patients without airway obstruction were studied. One subject had primary alveolar hypoventilation with normal body weight, pulmonary function, and nocturnal sleep record. Two subjects were massively obese ( 137 and $230 \mathrm{~kg}$ ) without airway obstruction. Nocturnal sleep recording in one subject showed periodic breathing with occasional central apnea lasting less than $10 \mathrm{~s}$. Although no formal sleep study was performed in the other patient, apnea was observed on several occasions when the subject appeared to fall asleep while breathing on the mouthpiece. Patient data were compared to those of five normal subjects with mean \pm SD of age and weight similar to the patients. Informed consent was obtained from both the patients and the normal subjects.

Only patients with stable $\mathrm{CO}_{2}$ retention and pulmonary function for the previous 6 mo were selected. Studies were not performed during exacerbation of symptoms. Patients with a forced expiratory volume in $1 \mathrm{~s}\left(\mathrm{FEV}_{1}\right)$ of $<0.5$ liters were excluded. Most COPD patients were treated with theophylline preparations that were not changed during the study period. Patients were advised to avoid aspirin and respiratory depressants. Alcohol and caffeine were not ingested within $24 \mathrm{~h}$ of a study session. Concomitant medications were continued at the same dosage during all experimental conditions. Phlebotomy was performed for hematocrits greater than 55\%; all studies were performed at least 1 mo after this procedure.

Experimental design. A single-blind design was used in 17 patients with $\mathrm{CO}_{2}$ retention during the following experimental conditions: (a) control (no drug), (b) placebo (4 wk), (c) placebo (4 wk), and (d) MPA, $20 \mathrm{mg}$ orally three times daily for $4 \mathrm{wk}$. Measurements were obtained after $4 \mathrm{wk}$ of placebo or MPA. The sequence of experimental conditions was random except that at least one placebo period was completed before MPA. This randomization resulted in the following sequence in the 10 patients who lowered $\mathrm{PaCO}_{2}$ after MPA: (a) MPA-placebo-placebo, three patients; $(b)$ placebo-MPA-placebo, four patients; and (c) placebo-placeboMPA, three patients.

Measurements. Pulmonary function studies were performed during the placebo and MPA periods. Spirometry was performed with a Collins 13-liter water seal spirometer (Warren E. Collins, Inc., Braintree, Mass.) and results ex- pressed as percent predicted by Morris et al. (14). Singlebreath diffusion capacity $\left(\mathrm{DLCO}_{\mathrm{SB}}\right)$ was measured using a modified technique of Ogilvie et al. (15). Functional residual capacity was measured in a body plethysmograph using Boyle's law techniques. Resistance of the respiratory system was determined during inspiration (at 0.5 liters/s flow rate) and at end expiration by the forced oscillation technique at 4 and $10 \mathrm{~Hz}$ using an automated system for resistance of the respiratory system measurement similar to that described by Hyatt et al. (16).

Arterial blood samples were obtained from an indwelling brachial or radial artery catheter. During each study period, four to six blood specimens were drawn over a $20-30$-min period while the patient was supine, in a quiet laboratory, and breathing room air. The patient remained supine and breathed air through a mouthpiece attached to a two-way valve while continuous measurements were made of expired ventilation through a heated Fleisch No. 2 pneumotachograph with integration of the flow signal by an Electronics for Medicine pulmonary function plug-in integrator (Electronics for Medicine, Pleasantville, N. Y.) and breath-by-breath end-tidal $\mathrm{PCO}_{2}$ (LB2, Beckman Instruments Inc., Fullerton, Calif.) to insure steady-state conditions for blood sampling. Inspiratory and expiratory time $\left(T_{I}\right.$ and $\left.T_{E}\right)$ were obtained from the flow signal of the pneumotachograph. An arterial blood specimen was drawn over $1 \mathrm{~min}$ and analyzed at $37^{\circ} \mathrm{C}$ for $\mathrm{pH}$, $\mathrm{PaCO}_{2}$ and $\mathrm{PaO}_{2}$ with a Radiometer blood gas analyzer (Radiometer Co., Copenhagen, Denmark). Calibration of $\mathrm{PaO}_{2}$ and $\mathrm{PaCO}_{2}$ electrodes were frequently validated using tonometered blood (17). At the same time, mixed expired gas was obtained and analyzed for $\mathrm{CO}_{2}, \mathrm{O}_{2}$, and $\mathrm{N}_{2}$ with a gas chromatograph (QuinTron Instrument Co., Inc., Milwaukee, Wis.). Dead space, $\mathrm{O}_{2}$ consumption, $\mathrm{CO}_{2}$ production, and respiratory exchange ratio were then calculated. This sequence of measurements was then repeated while the subject breathed mixtures of 30,50 , and $100 \% \mathrm{O}_{2}$ for $5 \mathrm{~min}$.

While the patient was breathing room air, $\mathrm{O}_{2}$, and $\mathrm{CO}_{2}$, the mouth occlusion pressure and the maximal slope of the inspiratory pressure curve ( $\mathrm{dp} / \mathrm{dt} \max$ ) were obtained. A Statham PM5-E-0.2-350 pressure transducer (range, $\pm 15 \mathrm{~cm}$ $\mathrm{H}_{2} \mathrm{O}$; Statham Instruments, Inc., Oxnard, Calif.) measured changes in mouth pressure during random occlusions obtained $0.1 \mathrm{~s}$ after the onset of the occluded inspiration $\left(\mathrm{P}_{0.1}\right) . \mathrm{P}_{0.1}$ was expressed as the mean of 6-10 occlusions performed at least $30 \mathrm{~s}$ apart. The $\mathrm{dp} / \mathrm{dt} \max$ was obtained breath-by-breath and expressed as the mean of 25 breaths by electronically differentiating the inspiratory pressure signal measured at the mouth as described by Matthews and Howell (18) and by Skatrud et al. (6).

Carbon dioxide response studies were performed using a rebreathing technique as described by Read (19). Voluntary hyperventilation (VHV) maneuvers were performed in two different ways. First, the patient breathed as fast and deep as possible for $30 \mathrm{~s}$ with an arterial blood sample drawn between 15 and $30 \mathrm{~s}$. After a rest, a slower but deeper maneuver was performed for $60 \mathrm{~s}$ with arterial blood drawn between 30 and $60 \mathrm{~s}$. In both cases, the blood samples were obtained only after end-tidal $\mathrm{PCO}_{2}$ had achieved a relatively steady state.

Lumbar puncture was performed in seven patients during placebo and treatment periods and analyzed for MPA. The techniques for anaerobic sampling and acid-base analyses of lumbar spinal fluid have been described previously (17).

MPA levels in plasma and CSF were determined by radioimmunoassay as previously described (6).

Statistical differences between means were determined by combining analysis of variance for repeated measures over all four conditions (control vs. placebo I vs. placebo II vs. 
MPA) and the Student's $t$ test for paired comparisons. Placebovs. placebo tested reproducibility, control vs. placebo tested the placebo effect and placebo vs. MPA tested the MPA effect.

Reproducibility and placebo effect. We tested the reproducibility of all ventilatory, arterial blood gas, and inspiratory effort measurements during the resting, air-breathing state between test sessions. No systematic difference was noted between placebo sessions for any of the measured variables including expired minute ventilation ( $\dot{V} E)$, alveolar ventilation (VA), tidal volume (VT), respiratory frequency (f), $\mathbf{P}_{\mathbf{0 . 1}}$, $\mathrm{dp} / \mathrm{dt} \max , \mathrm{pH}$, and $\mathrm{PaCO}_{2}(P>0.1)$. Random variability of differences between mean values for individual patients on two placebo sessions was obtained by dividing the standard error of the differences between paired measurements by the grand mean and expressing as a percentage. Random variability was as follows: (a) $\mathrm{VE}_{\mathrm{E}}, \dot{\mathrm{V}}_{\mathrm{A}}, \mathrm{VT}$, and $\mathrm{f}( \pm 2-4 \%)$; (b) $\mathrm{P}_{0.1}$ and $\mathrm{dp} / \mathrm{dt} \max ( \pm 8-9 \%)$; and $(c) \mathrm{pH}$ and $\mathrm{PaCO}_{2}( \pm 1 \%)$.

\section{RESULTS}

$\mathrm{CO}_{2}$ retainers es. normals. $\mathrm{CO}_{2}$ retainers were compared to normals to determine factors associated with $\mathrm{CO}_{2}$ retention (Tables I and II). Alveolar ventilation was low in spite of a normal minute ventilation to $\mathrm{CO}_{2}$ production ratio $\left(\dot{\mathrm{V}} \mathrm{E} / \mathrm{VCO}_{2}=46 \pm 3\right.$ vs. $47 \pm 3$ in normals). Indices of respiratory center drive $\left(\mathrm{P}_{0.1}\right.$ and $\mathrm{dp} / \mathrm{dt} \max )$ were 76 and $42 \%$ greater than normal
$(P<0.05) . \mathrm{T}_{\mathrm{I}}$ was short $(70 \%$ of normal $[P<0.05])$, tidal volume was low (33\% of normal $[P<0.01])$ and frequency was high ( $21 \%$ of normal). Dead space to tidal volume ratio was high ( $0.63 \mathrm{vs.} 0.39$ in normals) due to both an increase in physiologic dead space and decrease in tidal volume.

Correctors vs. noncorrectors. We expected, a priori, that some patients would and some would not lower their $\mathrm{PaCO}_{2}$ on MPA. We intended to compare characteristics of these patients in an attempt to identify factors that might predict a positive or negative response to the therapy. With our documentation of measurement reproducibility and patient stability and through our random application of MPA and placebo conditions, we felt justified in identifying retrospectively those patients who did and those patients who did not "correct" their $\mathrm{PaCO}_{2}$ after MPA. Correctors were defined as those patients who lowered $\mathrm{PaCO}_{2}$ at least $5 \mathrm{~mm} \mathrm{Hg} \quad(P<0.05$ compared to pre-MPA placebo) after MPA, whereas noncorrectors did not lower $\mathrm{PaCO}_{2}$ after MPA.

Three correctors were obese ( $>20 \%$ of ideal weight) and two noncorrectors (S.M. and J.H.) were massively obese, weighing 150 and $200 \mathrm{~kg}$, respectively. Meas-

TABLE I

Acid-Base Measurement during Placebo and MPA

\begin{tabular}{|c|c|c|c|c|c|}
\hline & \multicolumn{2}{|c|}{$\begin{array}{l}\text { Correctors* } \\
(n=10)\end{array}$} & \multicolumn{2}{|c|}{$\begin{array}{l}\text { Noncorrectors } \downarrow \\
\quad(n=7)\end{array}$} & \multirow{2}{*}{$\begin{array}{l}\text { Normals } \\
(n=5)\end{array}$} \\
\hline & Placebo & MPA & Placebo & MPA & \\
\hline Age, $y r$ & $\begin{array}{l}56 \pm 2 \\
(46-67) \S\end{array}$ & & $\begin{array}{c}54 \pm 4 \\
(37-68)\end{array}$ & & $\begin{array}{l}56 \pm 2 \\
(53-61)\end{array}$ \\
\hline Weight, $k g$ & $\begin{array}{l}92 \pm 5 \\
(56-130)\end{array}$ & & $\begin{array}{c}96 \pm 21 \\
(45-205)\end{array}$ & & $\begin{array}{l}107 \pm 13 \\
(81-120)\end{array}$ \\
\hline \multicolumn{6}{|l|}{ Acid-base } \\
\hline $\mathrm{PCO}_{2}, m m H g$ & $\begin{array}{c}51 \pm 19 \\
(44-59)\end{array}$ & $43 \pm 1^{\prime \prime}$ & $\begin{array}{c}54 \pm 39 \\
(46-66)\end{array}$ & $54 \pm 3$ & $\begin{array}{c}38 \pm 1 \\
(37-40)\end{array}$ \\
\hline$[\mathrm{H}+]$, nmollliter & $39.8 \pm 1$ & $38.2 \pm 1.0^{\prime \prime}$ & $41.4 \pm 1$ & $40.7 \pm 0.7$ & $38.7 \pm 1.6$ \\
\hline$\left[\mathrm{HCO}_{3}^{-}\right]$, meq/liter & $\begin{array}{c}31.2 \pm 1.09 \\
(27.8-35.6)\end{array}$ & $28.5 \pm 0.6^{\prime \prime}$ & $\begin{array}{c}31.6 \pm 1.49 \\
(27.7-36.7)\end{array}$ & $31.4 \pm 1.7$ & $\begin{array}{c}25 \pm 0.8 \\
(23.2-27.2)\end{array}$ \\
\hline $\mathrm{Po}_{2}, m m H g$ & $\begin{array}{c}52 \pm 2 \\
(45-63)\end{array}$ & $57 \pm 2^{\prime \prime}$ & $\begin{array}{c}48 \pm 2 \\
(40-56)\end{array}$ & $46 \pm 3$ & \\
\hline (A-a) $\mathrm{PO}_{2}, m m H g$ & $29 \pm 1$ & $36 \pm 2^{\prime \prime}$ & $30 \pm 3$ & $29 \pm 3$ & \\
\hline Hematocrit, $\%$ & $54 \pm 19$ & $45 \pm 2^{\prime \prime}$ & $54 \pm 2 \rrbracket$ & $55 \pm 3$ & $45 \pm 1$ \\
\hline \multicolumn{6}{|l|}{$\mathrm{CSF}$} \\
\hline$[\mathrm{H}+]$, nmollliter & $50.6 \pm 1$ & $48.3 \pm 1^{11}$ & & & \\
\hline $\mathrm{PCO}_{2}, \mathrm{~mm} \mathrm{Hg}$ & $62 \pm 1$ & $53 \pm 1^{11}$ & & & \\
\hline$\left[\mathrm{HCO}_{3}^{-}\right]$, meq/liter & $28.9 \pm 0.6$ & $25 \pm 0.6^{\prime \prime}$ & & & \\
\hline
\end{tabular}

All values are mean $\pm S E M$.

* Patients who significantly lowered $\mathrm{PaCO}_{2}$ during MPA administration $(n=10)$.

$\$$ Patients who did not lower $\mathrm{PaCO}_{2}$ after MPA $(n=7)$.

$\S$ Ranges are given in parentheses.

" $P<0.05$ compared to placebo.

I $P<0.05$ compared to normals. 
TABLE II

Ventilatory Measurement during Placebo and MPA

\begin{tabular}{|c|c|c|c|c|c|}
\hline & \multicolumn{2}{|c|}{$\begin{array}{l}\text { Correctors* } \\
(n=10)\end{array}$} & \multicolumn{2}{|c|}{$\begin{array}{l}\text { Noncorrectors } ₫ \\
\quad(n=7)\end{array}$} & \multirow{2}{*}{$\begin{array}{l}\text { Normals } \\
(n=5)\end{array}$} \\
\hline & Placebo & MPA & Placebo & MPA & \\
\hline \multicolumn{6}{|l|}{ Ventilation } \\
\hline$\dot{\mathrm{V}} \mathrm{E}$, liter/min & $9.4 \pm 0.9$ & $10.9 \pm 0.9^{\prime \prime}$ & $9.7 \pm 1.0$ & $10.9 \pm 0.8$ & $12.3 \pm 0.9$ \\
\hline$\dot{\mathrm{V}} \mathrm{CO}_{2}$, liter/min & $0.20 \pm 0.02$ & $0.20 \pm 0.02$ & $0.22 \pm 0.02$ & $0.23 \pm 0.02$ & $0.26 \pm 0.03$ \\
\hline$\dot{\mathrm{V}} \mathrm{A}$, liter/min & $3.5 \pm 0.9 \S$ & $4.2 \pm 0.4^{\prime \prime}$ & $3.5 \pm 0.9 \S$ & $3.8 \pm 0.5$ & $6.5 \pm 0.2$ \\
\hline f, breaths/min & $17 \pm 1$ & $17 \pm 1$ & $17 \pm 2$ & $19 \pm 2^{\prime \prime}$ & $14 \pm 1$ \\
\hline Vт, liter & $0.55 \pm 0.03 \S$ & $0.61 \pm 0.03^{\prime \prime}$ & $0.60 \pm 0.3 \S$ & $0.56 \pm 0.06$ & $0.88 \pm 0.04$ \\
\hline $\mathrm{VD} / \mathrm{VT}$ & $0.63 \pm 0.02 \S$ & $0.62 \pm 0.02$ & $0.63 \pm 0.05 \S$ & $0.63 \pm 0.05$ & $0.39 \pm 0.07$ \\
\hline \multicolumn{6}{|c|}{ Ventilatory indices and timing } \\
\hline & $3.4 \pm 0.7 \S$ & $\begin{array}{l}3.8 \pm 0.4^{\prime \prime} \\
34+4\end{array}$ & $2.6 \pm 0.5 \S$ & $\begin{array}{c}3.3 \pm 0.4 \\
29+5\end{array}$ & $\begin{array}{l}1.7 \pm 0.3 \\
19 \pm 6\end{array}$ \\
\hline $\begin{array}{l}\mathrm{dp} / \mathrm{dt} \max , \mathrm{cm}_{2} \mathrm{H}_{2} \mathrm{O} / \mathrm{s} \\
\mathrm{VT} / \mathrm{TI} \text {, liter/s }\end{array}$ & $\begin{array}{c}29 \pm 38 \\
0.52 \pm 0.04\end{array}$ & $\begin{array}{c}34 \pm 4 \\
0.58 \pm 0.02^{\prime \prime}\end{array}$ & $0.51 \pm 0.04$ & $0.52 \pm 0.04$ & $\begin{array}{c}19 \pm 0 \\
0.51 \pm 0.05\end{array}$ \\
\hline $\mathrm{T} \mathbf{}, s$ & $1.31 \pm 0.13 \S$ & $1.31 \pm 0.15$ & $1.42 \pm 0.17 \S$ & $1.32 \pm 0.10$ & $1.80 \pm 0.33$ \\
\hline$T_{1} / T_{\text {Tot }}$ & $0.38 \pm 0.02$ & $0.36 \pm 0.02$ & $0.36 \pm 0.02$ & $0.37 \pm 0.02$ & $0.40 \pm 0.02$ \\
\hline
\end{tabular}

All values are mean $\pm S E M$. VD, dead space volume; $T_{\text {Tot }}$, total respiratory cycle time.

* Patients who significantly lowered $\mathrm{PaCO}_{2}$ during MPA administration $(n=10)$.

$\$$ Patients who did not lower $\mathrm{PaCO}_{2}$ after MPA $(n=7)$.

$\$ P<0.05$ compared to normals.

" $P<0.05$ compared to placebo.

urements of acid-base status, ventilation and respiratory cycle timing during placebo are shown for correctors and noncorrectors in Tables I and II. No significant differences between the groups were noted for any of the variables studied $(P>0.01)$. Similarly, average values for lung volumes and airway mechanics were not statistically different in correctors and noncorrectors $(P>0.05)$ (Table III). However, when only patients with COPD are included in the analysis, the mean diffusion capacity was lower in noncorrectors compared to correctors $(12.8 \mathrm{vs} .19 .1 \mathrm{ml} / \mathrm{min}$ per $\mathrm{mmHg}$, $P<0.02)$, whereas other variables showed no difference $(P>0.05)$.

Of all 17 patients, 14 had moderate to severe COPD $\left(\mathrm{FEV}_{1}\right.$ /forced vital capacity, $\left.23-58 \%\right)$ with high inspiratory resistance $(120-280 \%$ predicted) and functional residual capacity (121-238\% predicted). No obstructive airway disease was present in two massively obese noncorrectors (S.M. and J.H.) and one nonobese corrector (V.W.). Two of the noncorrectors (C.S. and M.P.) had lobectomies resulting in lower lung volumes and reduced diffusion capacity.

MPA response. No systematic difference was noted between two placebo studies performed 1-3 mo apart for any of the variables, confirming the stability of the study population and the reproducibility of measurements.

Mean and individual patient blood gases and acidbase status during MPA therapy are shown in Table I and Fig. 1. A true drug effect of MPA was docu- mented in 10 of 17 patients who significantly lowered $\mathrm{PaCO}_{2}$ a mean of $8 \pm 1 \mathrm{~mm} \mathrm{Hg}(5-12 \mathrm{~mm} \mathrm{Hg})$. After withdrawal of MPA, 8 of 10 correctors returned $\mathrm{PaCO}_{2}$ to within $\pm 2 \mathrm{~mm} \mathrm{Hg}$ of pre-MPA placebo values. In the remaining two patients, $\mathrm{PaCO}_{2}$ increased 5 and $6 \mathrm{~mm} \mathrm{Hg}$ after withdrawal of MPA to within 4 and $6 \mathrm{~mm} \mathrm{Hg}$, respectively, of placebo values. Arterial $[\mathrm{H}+]$ became alkaline to placebo $(P<0.05)$ and $\left[\mathrm{HCO}_{3}^{-}\right]$decreased as $\mathrm{CO}_{2}$ retention was diminished and maintained at lower levels compared to placebo. Correctors raised $\mathrm{PaO}_{2}$ a mean of $5 \pm 2 \mathrm{~mm} \mathrm{Hg}$ $(P<0.05)$ with 8 of 10 patients showing an increase (2-14 mm Hg). The alveolar-arterial oxygen difference, (A-a) $\mathrm{PO}_{2}$, widened in all correctors from a mean of $29 \pm 1$ to $36 \pm 2 \mathrm{~mm} \mathrm{Hg}(P<0.01)$. The hematocrits decreased significantly from $54 \pm 2$ to $48 \pm 2(P<0.02)$. In contrast, the noncorrectors showed no significant change in acid base status, $\mathrm{PaO}_{2}$, or hematocrit after MPA, although two patients lowered $\mathrm{PaCO}_{2} 3 \mathrm{~mm} \mathrm{Hg}$.

Responses of ventilatory indices and timing to MPA are shown in Table II (mean values) and Fig. 2 (individual values). In the correctors, minute ventilation to $\mathrm{CO}_{2}$ production ratio $\left(\dot{\mathrm{V}} / \mathrm{V}_{\mathrm{CO}}\right)$ increased $15 \pm 4 \%(P<0.01)$, with no significant change in $\mathrm{CO}_{2}$ production. The tidal volume increased significantly, a mean of $11 \pm 4 \%(P<0.02)$ with 8 of 10 correctors showing increases. Inspiratory time remained abnormally short $(1.31 \pm 0.15$ vs. $1.80 \pm 0.33 \mathrm{~s}$ in normals $)$. Frequency was not significantly changed with only 4 of 10 correctors showing small increases. Indices of 
TABLE III

Lung Volumes and Mechanics during Placebo

\begin{tabular}{|c|c|c|c|c|}
\hline & \multicolumn{2}{|c|}{$\begin{array}{l}\text { Correctors* } \\
(n=10)\end{array}$} & \multicolumn{2}{|c|}{$\begin{array}{l}\text { Noncorrectors } 1 \\
\quad(n=7)\end{array}$} \\
\hline & Actual & Percent predicted & Actual & Percent predicted \\
\hline $\mathrm{VC}$, liter & $2.78 \pm 0.98$ & $67.3 \pm 3.9$ & $2.65 \pm 0.37$ & $60 \pm 7$ \\
\hline FRC, liter & $5.64 \pm 0.67$ & $227 \pm 27$ & $5.54 \pm 0.74$ & $212 \pm 35$ \\
\hline $\mathrm{DLCO}_{\mathrm{SB}}, \mathrm{ml} / \mathrm{min} / \mathrm{mm} \mathrm{Hg}$ & $20 \pm 2$ & $90 \pm 5$ & $16 \pm 4$ & $65 \pm 11$ \\
\hline $\mathrm{FEV}_{1}$, liter & $\begin{array}{c}1.19 \pm 0.15 \\
(0.69-1.95)\end{array}$ & $42 \pm 5$ & $\begin{array}{c}1.31 \pm 0.43 \\
(0.50-3.01)\end{array}$ & $39 \pm 11$ \\
\hline $\mathrm{FEV}_{1} / \mathrm{FVC}, \%$ & $50 \pm 5$ & & $49 \pm 9$ & \\
\hline $\begin{array}{l}\mathrm{V}_{\text {maxso }} \text {, liter/s } \\
\text { Rrs } 4 \mathrm{~Hz}, \mathrm{~cm} \mathrm{H} \mathrm{H}_{2} \mathrm{O} / \text { liter } / \mathrm{s}\end{array}$ & $0.45 \pm 0.09$ & $10.0 \pm 2$ & $0.75 \pm 0.43$ & $16 \pm 9$ \\
\hline Inspiratory & $2.9 \pm 0.3$ & $161 \pm 17$ & $3.1 \pm 0.7$ & $172 \pm 39$ \\
\hline Expiratory & $4.8 \pm 0.6$ & $267 \pm 33$ & $5.6 \pm 1.4$ & $311 \pm 100$ \\
\hline $\begin{array}{l}\text { VHV liter/min } \S \\
\Delta \mathrm{PaCO}_{2} \text { with VHV, } m m \mathrm{Hg}^{\prime \prime}\end{array}$ & $\begin{array}{c}36 \pm 5 \\
-10 \pm 2 \\
(-5 \text { to }-22)\end{array}$ & $26 \pm 4$ & $\begin{array}{c}42 \pm 15 \\
-8 \pm 3 \\
\text { (0 in four of } \\
\text { seven patients } \\
-9 \text { to }-21 \text { in } \\
\text { three of seven) }\end{array}$ & $30 \pm 11$ \\
\hline
\end{tabular}

All values are mean \pm SEM. VC, vital capacity; FRC, functional residual capacity; FVC, forced vital capacity;

Rrs, resistance of the respiratory system.

* Patients who significantly lowered $\mathrm{PaCO}_{2}$ during MPA administration.

$\$$ Patients who did not lower $\mathrm{PaCO}_{2}$ during MPA administration.

$\$$ Maximal voluntary hyperventilation sustained for $30-60 \mathrm{~s}$.

"Refers to change in $\mathrm{PaCO}_{2}$ during voluntary hyperventilation.

inspiratory effort $\left(\mathrm{P}_{0.1}, \mathrm{dp} / \mathrm{dt} \max\right.$, and $\left.\mathrm{VT} / \mathrm{T}_{1}\right)$ were increased $11-14 \%(P<0.05)$.

Lung volumes, airway resistance, and $\mathrm{DLCO}_{\mathrm{SB}}$ did not change. Oxygen consumption and respiratory exchange ratio did not change. Most patients increased oral temperatures after MPA $\left(-0.02-+0.6^{\circ} \mathrm{C}\right)$, but the mean change $\left(36.8 \pm 0.2^{\circ} \mathrm{C}\right)$ was not statistically significant $(P>0.05)$.

In the noncorrectors, mean minute ventilation increased $18 \pm 8 \%$ with five of seven patients showing a ventilatory response $(P>0.05)$. However, the minute ventilation to $\mathrm{CO}_{2}$ production ratio increased only $9 \pm 6 \%$ $(P>0.05)$ (Fig. 2 and Table II). $\mathrm{PaCO}_{2}$ showed no significant change $(0--3 \mathrm{~mm} \mathrm{Hg})(P>0.1)$. The noncorrectors $(n=7)$ were divided into three groups based on response to MPA. First, no increase in minute ventilation was noted after MPA in two patients (R.S. and D.B.). Second, increased minute ventilation was associated with a 25 and $31 \%$ increase in $\dot{\mathrm{VCO}}_{2}$ with no change in $\mathrm{PaCO}_{2}$ in two patients (C.S. and M.P.). Third, increased minute ventilation and increased $\dot{\mathrm{V}} \mathrm{E} / \mathrm{V} \mathrm{CO}_{2}$ was achieved by increasing frequency rather than tidal volume in three patients (S.M., J.H., and R.K.). Consequently, $\mathrm{PaCO}_{2}$ decreased only $7 \%$ despite a $13 \%$ increase in $\dot{\mathrm{V}} / \mathrm{V}_{\mathrm{CO}_{2}}$. The functional residual capacity increased in five of seven noncorrectors (range, 5-20\%). Otherwise, lung volumes, airway resistance, and $\mathrm{DLCO}_{\mathrm{SB}}$ did not change.

The effect of MPA on resting $\mathrm{PaCO}_{2}$ in the correctors was similar whether the patients were breathing air at a mean $\mathrm{PaO}_{2}$ of $52 \mathrm{~mm} \mathrm{Hg}\left(\Delta \mathrm{PaCO}_{2}=-8 \pm 1 \mathrm{~mm} \mathrm{Hg}\right)$ or during acute correction of hypoxemia with $50 \%$ oxygen at a mean $\mathrm{PaO}_{2}$ of $169 \mathrm{~mm} \mathrm{Hg}\left(\Delta \mathrm{PaCO}_{2}=-9 \pm 1 \mathrm{~mm} \mathrm{Hg}\right)$ (Table IV). Similarly, the acute depressant effects of hyperoxia on ventilation and ventilatory effort were similar before $\left(\Delta \mathrm{PaCO}_{2}=4 \pm 1 \mathrm{~mm} \mathrm{Hg}\right)$ and after $\left(\Delta \mathrm{PaCO}_{2}=3 \pm 1 \mathrm{~mm} \mathrm{Hg}\right) \mathrm{CO}_{2}$ correction via MPA therapy. Noncorrectors showed no difference in the response to hyperoxia before or after MPA therapy.

Lumbar CSF acid-base status was measured in six of ten correctors (Table I). $\mathrm{PCO}_{2},[\mathrm{H}+]$, and $\left[\mathrm{HCO}_{3}\right]$ decreased significantly in CSF, and these changes were similar to those in arterial blood.

Assay of MPA related materials in plasma was $59 \pm 9$ $\mathrm{ng} / \mathrm{ml}$ in the correctors compared to $54 \pm 8 \mathrm{ng} / \mathrm{ml}$ in the noncorrectors $(P>0.2)$. CSF levels increased to $4.8 \pm 0.5 \mathrm{ng} / \mathrm{ml}$ during treatment, which was $8 \%$ of the increase observed in plasma. In the two obese noncorrectors, MPA dose was raised from 60 to $110 \mathrm{mg}$ daily, producing a mean plasma level of $68 \mathrm{ng} / \mathrm{ml}$ with no decrease in $\mathrm{PaCO}_{2}$ compared to placebo.

The responses to $\mathrm{VHV}$ and exogenous $\mathrm{CO}_{2}$ were 


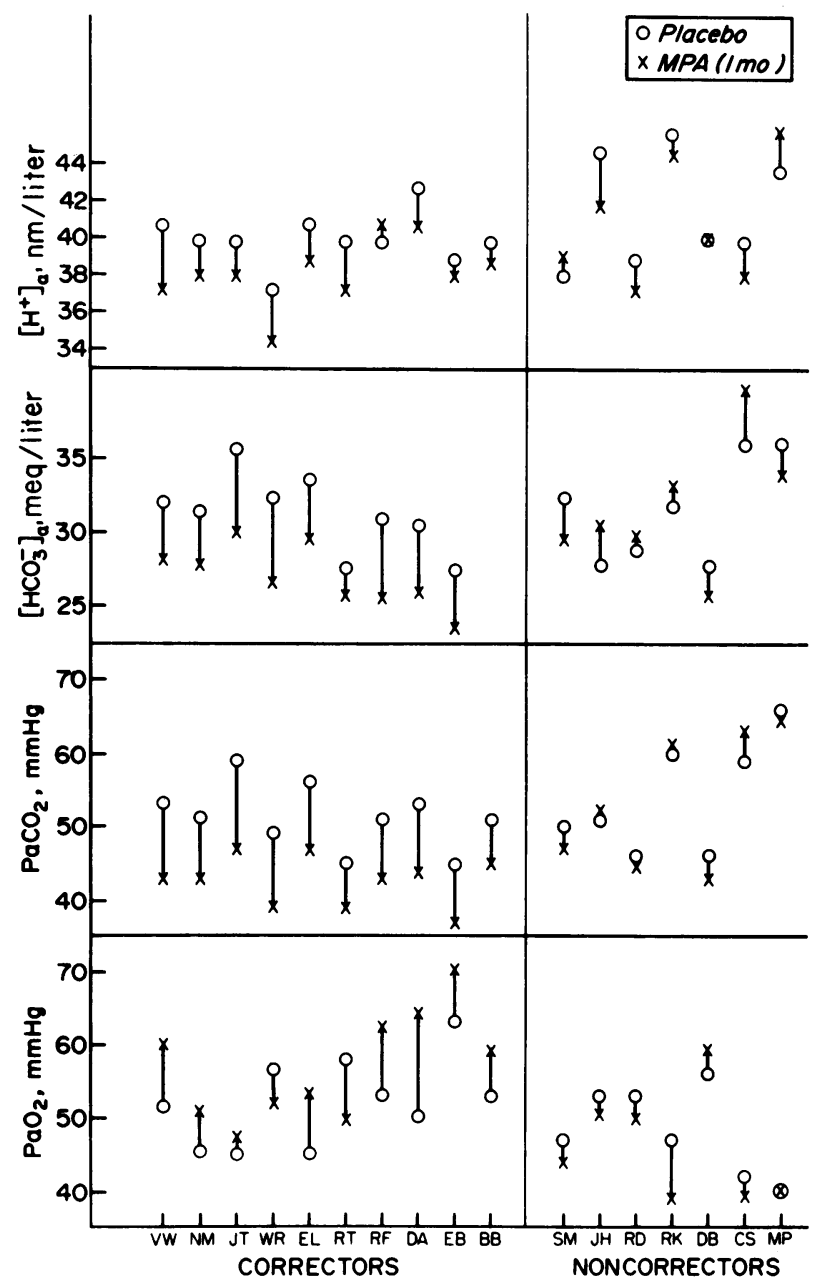

FIGURE 1 Effect of MPA on arterial blood in correctors vs. noncorrectors. Points represent the mean of three to five measurements in an individual patient during placebo and after MPA. Correctors are those patients who significantly lowered $\mathrm{PaCO}_{2}$ after MPA. Noncorrectors did not lower $\mathrm{PaCO}_{2}$ after MPA.

studied in correctors and noncorrectors to see if they were correlated with the response to MPA. VHV increased $\dot{\mathrm{VE}}$ and decreased $\mathrm{PaCO}_{2}$ at least $5 \mathrm{~mm} \mathrm{Hg}$ in all correctors (Fig. 3A). Of the seven noncorrectors, four did not lower $\mathrm{PaCO}_{2}$ after VHV. Two massively obese noncorrectors (S.M. and J.H.) without obstructive airway disease could easily increase $\dot{V} E$ and lower $\mathrm{PaCO}_{2}$. The response to exogenous $\mathrm{CO}_{2}$ in terms of VE, VT, f, or dp/dt max did not predict responsiveness to MPA nor did they change consistently after MPA (Fig. 3B).

\section{DISCUSSION}

This study has examined the chronic effect of MPA treatment on ventilatory drive and acid-base status. We

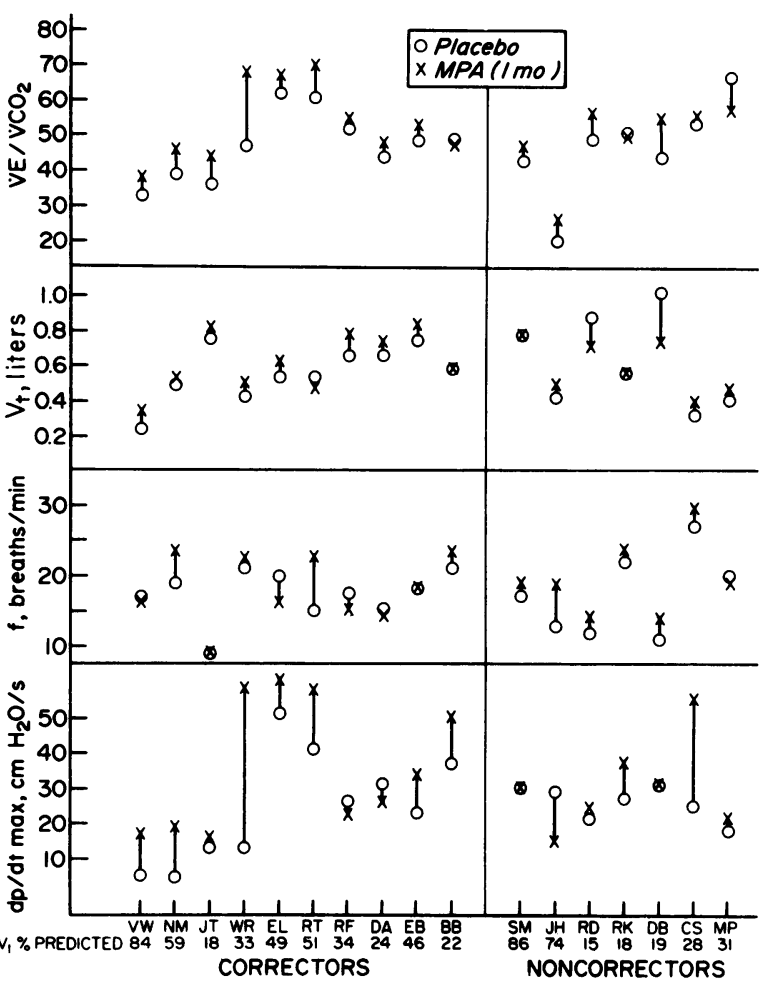

FIGURE 2 Effect of MPA on ventilatory indices in correctors and noncorrectors. $\mathrm{FEV}_{1} \%$ predicted is shown for each patient during the placebo period. Correctors are those patients who significantly lowered $\mathrm{PaCO}_{2}$ after MPA. Noncorrectors did not lower $\mathrm{PaCO}_{2}$ after MPA.

have shown that $\mathrm{CO}_{2}$ retention in patients with high mechanical loads on the lung occurred concomitantly with higher than normal inspiratory drive or effort, normal minute ventilation, and was due primarily to tachypneic, high dead space ventilation. With MPA therapy, most patients showed a significant correction of their $\mathrm{CO}_{2}$ retention with prominent features of their response including increased tidal volume and increased inspiratory effort. Our ability to distinguish

TABLE IV

Effects of Acute Correction of Hypoxemia in Correctors before and after MPA $(n=10)$

\begin{tabular}{lccccc}
\hline & \multicolumn{2}{c}{ Placebo } & & \multicolumn{2}{c}{ MPA } \\
\cline { 2 - 3 } \cline { 5 - 6 } $\mathrm{FiO}_{2}$ & 0.21 & $0.50^{*}$ & & 0.21 & $0.50^{*}$ \\
\hline $\mathrm{PaO}_{2}$ & $52 \pm 2$ & $142 \pm 13$ & & $57 \pm 2$ & $169 \pm 16$ \\
$\mathrm{PaCO}_{2}$ & $51 \pm 1$ & $55 \pm 1$ & & $43 \pm 1$ & $46 \pm 2$ \\
$\dot{\mathrm{V}}$ & $9.4 \pm 0.9$ & $9.0 \pm 0.9$ & & $10.9 \pm 0.9$ & $10.5 \pm 0.9$ \\
$\dot{\mathrm{V}}$ & $3.5 \pm 0.9$ & $3.2 \pm 0.4$ & & $4.2 \pm 0.4$ & $4.0 \pm 0.6$ \\
$\mathrm{P}_{0.1}$ & $3.4 \pm 0.7$ & $2.8 \pm 0.64$ & & $3.8 \pm 0.4$ & $3.2 \pm 0.7$ \\
\hline
\end{tabular}

* Measurements were taken after 5 min of hyperoxia. $\mathrm{F}_{1} \mathrm{O}_{2}$, fractional concentration of $\mathrm{O}_{2}$ in inspired gas. 


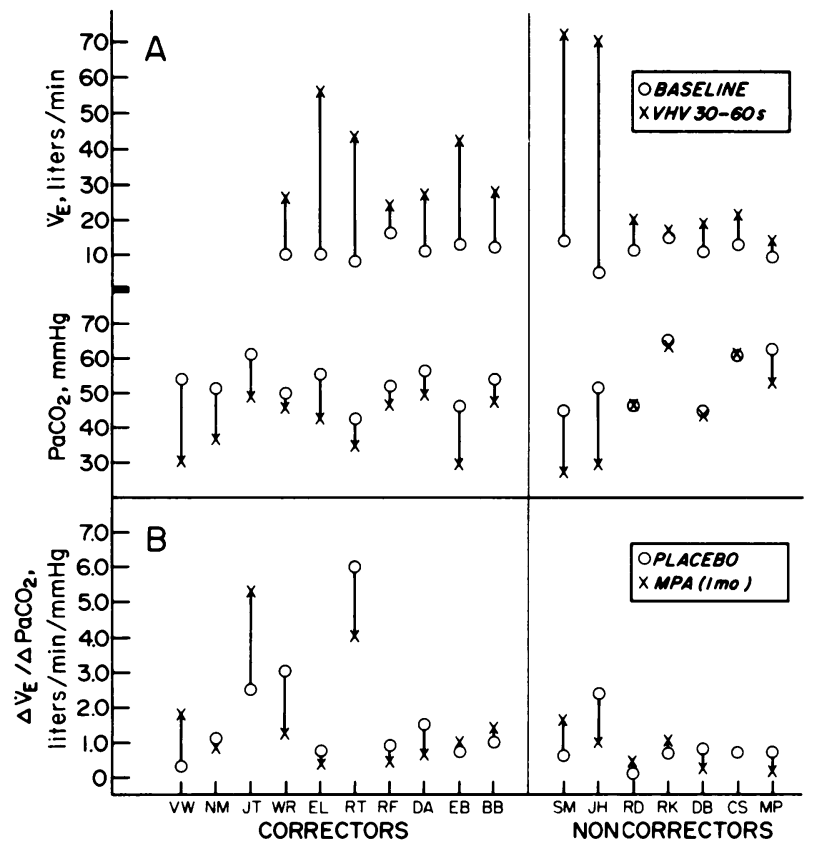

Figure 3 Ventilatory responses to $\mathrm{VHV}$, and exogenous $\mathrm{CO}_{2}$ in correctors and noncorrectors. A illustrates the ventilatory and $\mathrm{PaCO}_{2}$ change during VHV. Measurements in A were taken during the placebo period, and baseline represents steady-state air breathing on the mouthpiece. B illustrates the slope of the ventilatory response to exogenous $\mathrm{CO}_{2}$ both before and after MPA.

between correctors and noncorrectors was limited, but common prerequisites to achieving a decreased $\mathrm{PaCO}_{2}$ after MPA were the ability to lower $\mathrm{PaCO}_{2}$ with voluntary hyperventilation and an increase in tidal volume with chronic MPA therapy.

Response to MPA therapy. Orally administered MPA produced a significant hyperpnea in most patients and lowered $\mathrm{PaCO}_{2}$ a mean of $8 \pm 1 \mathrm{~mm} \mathrm{Hg}$ in 10 of 17 patients. We believe that this response to MPA represented a true drug effect rather than response to placebo or random variability. First, a single-blind randomized study design minimized suggestibility and placebo effect. Secondly, patient stability over a 1-3-mo interval was documented by showing no systematic difference between two placebo studies. This made it unlikely that the observed effect was due to the random fluctuation of a group of patients undergoing intensive study. Finally, our demonstration of between-day reproducibility of measurements for air breathing, resting conditions (see Methods) and a statistically significant difference between treatment and both placebo periods made it unlikely that the observed responses to MPA were due to random or systematic variability of the measurements made or the physiologic conditions under study. In addition, all correctors increased $\mathrm{PaCO}_{2}$ after withdrawal of MPA with 8 of 10 returning to pre-MPA levels. Therefore, we concluded that the significant decrease in $\mathrm{PaCO}_{2}$ associated with increased tidal volume and increased inspiratory effort represented a true ventilatory stimulant effect of MPA.

Previous clinical studies have also shown increases in minute and alveolar ventilation after progesterone administration in some patients with COPD. Tyler studied nine patients with COPD, all of whom lowered $\mathrm{PaCO}_{2}$ a mean of $8 \mathrm{~mm} \mathrm{Hg}$ and increased minute and alveolar ventilation 20 and $24 \%$, respectively (10). Cullen et al. (11), whose patients had more severe airway obstruction than Tyler's (mean $\mathrm{FEV}_{1}, 0.38$ vs. 0.6 liters), found only three of seven patients who could lower $\mathrm{PaCO}_{2}$ after progesterone (11). Therefore, like progesterone, oral MPA can increase minute ventilation in most and normalize $\mathrm{PaCO}_{2}$ in some chronic $\mathrm{CO}_{2}$ retainers by ventilatory stimulation in spite of severe mechanical impairment.

Neither the mode nor site of ventilatory stimulation by MPA is apparent from these data. Our findings rule out any'significant mediator role for measurable changes in arterial plasma or CSF acid-base status, which both changed in an alkaline direction, and in metabolic rate or core temperature, which were unchanged. We did not detect significant changes in lung mechanics, but could not exclude the possibility that MPA may have exerted some of its ventilatory effect through changes in either airway or parenchymal mechanics (20) or in respiratory muscle function. At this time, we can only point out that increased MPA levels were noted in plasma and CSF in normals (6) and in patients and suggest that MPA or its metabolites are potentially available to receptor sites in these areas.

Correctors is. noncorrectors. The noncorrectors represented a heterogenous group of disease states that may have influenced the response to MPA. Specifically, they comprise a series of seven patients: three with severe obstructive disease, two with lobectomies plus obstructive disease, and two with obesity and no obstructive disease. Whereas no single criterion was identifiable, we did observe important individual differences in the neuromuscular and metabolic responses to drug-induced increases in inspiratory effort that had predictive value.

Two of the three patients with severe obstructive disease did not increase VE chronically with MPA or acutely with voluntary hyperventilation. In contrast, all remaining noncorrectors increased $\dot{V} E$ with MPA. These two patients had the lowest percent predicted $\mathrm{FEV}_{1}(15$ and $19 \%)$, diffusion capacity (7.3 and 12.4 $\mathrm{ml} / \mathrm{min}$ per $\mathrm{mmHg}$ ) and the highest functional residual capacity (6.13 and 7.35 liters) suggesting a more severe mechanical impairment than patients with COPD who corrected. We concluded that flow limitation and ventilation-perfusion abnormality were too severe in these 
patients to permit a ventilatory response to any stimulus, acute or chronic.

The two noncorrectors with lobectomies showed increases in $\dot{V}_{E}$ and $\dot{V}_{A}$ which were comparable to correctors, but $\mathrm{CO}_{2}$ production increased proportionally resulting in no decrease in $\mathrm{PaCO}_{2}$. Whether a drug-induced increase in $\dot{\mathrm{V}} \mathrm{CO}_{2}$ caused an isocapnic hyperpnea or if a drug-induced increase in $\dot{V E}$ caused a proportional increase in $\mathrm{V}_{\mathrm{CO}_{2}}$ from increased activity of respiratory muscles, could not be determined with certainty. Since a primary increase in $\mathrm{VCO}_{2}$ has not been demonstrated in normals given MPA (6), the most likely mechanism may be that proposed by Riley (21), whereby the increased work of breathing caused by chronic increases in ventilation may produce more carbon dioxide than it eliminates. Therefore, the response in these patients was also limited by the work of breathing not only as a result of obstructive disease but also due to other mechanical and gas exchange characteristics of those lungs.

The importance of an increased tidal volume rather than frequency response in normalizing $\mathrm{PaCO}_{2}$ was illustrated by comparing correctors to two obese patients and one patient with severe airway obstruction who did not correct $\mathrm{PaCO}_{2}$ after MPA. Correctors achieved their increased $\dot{V}_{E}$ and $\dot{V} A$ primarily through an increased VT with no change in either (an abnormally short) inspiratory time or (high) breathing frequency. In these three noncorrectors, who increased $\mathrm{P}_{0.1}, \dot{\mathrm{VE}}$, and $\dot{\mathrm{VE}} / \mathrm{VCO}_{2}$ without a change in $\mathrm{PaCO}_{2}$, the respiratory cycle timing after MPA was altered, decreasing $T_{1}$ further below its already subnormal values and increasing breathing frequency. Although the frequency response increased $\dot{V}_{E}$, this was much less effective in increasing $\dot{V}_{A}$ than the increase in tidal volume noted in correctors. Specifically, $\mathrm{PaCO}_{2}$ decreased only $7 \%$ in these three noncorrectors compared to $16 \%$ in the correctors despite similar increases in $\dot{V E}$ of $16-18 \%$. Although the number of these types of noncorrectors to MPA was small $(n=3)$, these findings indicate that a frequency response to MPA was insufficient to normalize $\mathrm{PaCO}_{2}$ compared to the tidal volume response noted in correctors.

In summary, most noncorrectors could not increase alveolar ventilation with any stimulus because of mechanical impairment. A prerequisite of the response to MPA was the ability to acutely lower $\mathrm{PaCO}_{2}$ $>5 \mathrm{~mm} \mathrm{Hg}$ after voluntary hyperventilation performed with either a rapid-shallow or slow-deep pattern. Conversely, a decrease in $\mathrm{PaCO}_{2}$ with voluntary hyperventilation did not assure a lowering of $\mathrm{PaCO}_{2}$ after MPA since other factors such as a tidal volume rather than frequency response may be required on a chronic basis.

We measured several other factors that did not predict responsiveness to MPA therapy. These in- cluded resting pulmonary function tests, initial (control) acid-base status or degree of hypoxemia, and the acute response to either intravenous doxapram hydrochloride or exogenous $\mathrm{CO}_{2}$ measured in terms of $\dot{V}_{\mathrm{E}}, \mathrm{dp} / \mathrm{dt}_{\max }, \mathrm{VT}$, or f. Further, in a related study using the same patients, we found little correlation between the chronic ventilatory response to normalization of plasma $\left[\mathrm{HCO}_{3}\right]$ via acetazalamide and that to MPA (22).

Determinants of chronic $\mathrm{CO}_{2}$ retention. The mechanism of chronic $\mathrm{CO}_{2}$ retention in patients with COPD remains controversial. The retention of $\mathrm{CO}_{2}$ is not closely correlated with the degree of airway obstruction. Alternatively, $\mathrm{CO}_{2}$ retention has been attributed to either subnormal ventilatory drive or "chemosensitivity" (23-26) or to abnormalities in respiratory cycle timing (13). We have attempted to identify the relative contributions of these factors to $\mathrm{CO}_{2}$ retention in our patient population by analysis of both the control data obtained in stable $\mathrm{CO}_{2}$ retention and the interpatient differences observed in response to chronic ventilatory stimulation via MPA.

The characteristics of our patients with COPD and $\mathrm{CO}_{2}$ retention were similar to those previously described (13, 27-29). High indices of mechanical load and abnormal ventilation-perfusion relationships were manifested by a high $\mathrm{A}-\mathrm{aO}_{2}$ difference and increased physiologic dead space. Augmented inspiratory effort in the face of increased mechanical load was documented by high $\mathrm{P}_{0.1}$ and normal mean inspiratory flow and minute ventilation relative to $\mathrm{CO}_{2}$ production, i.e., normal $\dot{\mathrm{V}} / \dot{\mathrm{V}} \mathrm{CO}_{2}$. A rapid, shallow pattern of breathing with an abnormally shortened inspiratory duration was ineffective in maintaining alveolar ventilation despite normal $\dot{\mathrm{V}} \mathrm{E} / \dot{\mathrm{V}} \mathrm{CO}_{2}$. We observed that whereas most patients increased inspiratory effort and $\mathrm{VE} / \mathrm{VCO}_{2}$ with MPA therapy, their chronic $\mathrm{CO}_{2}$ retention was corrected only when tidal volume was also increased and was not corrected when a further increase in breathing frequency contributed most to the increased minute ventilation. These findings are consistent with the view from previous studies of patients with and without $\mathrm{CO}_{2}$ retention that respiratory cycle timing, specifically a reduced $\mathrm{T}_{1}$, contributes to chronic $\mathrm{CO}_{2}$ retention and its removal (13).

On the other hand, it does not follow that a shortened inspiratory time, per se, will inevitably lead to $\mathrm{CO}_{2}$ retention and that inspiratory effort or drive is inconsequential as a determinant of $\mathrm{CO}_{2}$ retention or its correction. On the contrary, our prospective, longitudinal study showed that most patients on MPA therapy did not correct their original abnormality in respiratory cycle timing, (i.e., shortened $T_{1}$, high frequency, and high dead space volume (VD/VT), and yet were able to correct their $\mathrm{CO}_{2}$ retention by increasing their inspiratory effort and thereby normalizing tidal volume. Similarly, Bradley, et al. (30) noted 
that a shortened inspiratory time was not necessarily associated with hypercapnia in hypoxemic patients with COPD. These findings demonstrate that although neuromuscular inspiratory effort is high in chronic $\mathrm{CO}_{2}$ retention, it is inadequate in the presence of mechanical and ventilation-perfusion abnormalities to normalize arterial blood gases. A normocapnic state was produced in these patients only if chronic MPA therapy caused supernormal inspiratory effort, supernormal $\dot{\mathrm{V}} / \mathrm{V} \mathrm{CO}_{2}$ and normalization of tidal volume.

\section{ACKNOWLEDGMENTS}

We thank H. Rasmussen, B. Schultze, J. Vaughn, J. Bates, and D. Pegelow for technical assistance; D. G. Kaiser and the Upjohn Company for performing MPA assays and providing the MPA; L. W. Chosy and G. A. doPico for assisting with the spinal taps; and H. Hoffman and C. Burgess for preparation of the manuscript.

These studies were supported by National Heart, Lung, and Blood Institute grants 17540 and 20815, the University of Wisconsin Graduate School, National Heart, Lung, and Blood Institute Career Development Award 00149, and the Medical Research Service of the Veterans Administration.

\section{REFERENCES}

1. Hasselbalch, K. A. 1912. Ein beitrag zur(1912) respiration physiologia der graviditat. Scand. Arch. Physiol. 27: 1-12.

2. Hasselbalch, K. A., and S. A. Gammeltoft. 1915. Die neuralitatisie gravideson des gravidesn organismus. Biochem. Z. 68: 206-264.

3. Heerhaber, J., H. K. Loeschcke, and V. Westphal. 1948. Eine wirkung des progesterone auf die atmung. Pfluegers Archiv. Gesamte Physiol. Menschen Tiere. 250: 42-55.

4. Goodland, R. L., J. G. Reynolds, A. B. McCoord, and W. T. Pommerenke. 1953. Respiratory and electrolyte effects induced by estrogen and progesterone. Fertil. Steril. 4: 300-316.

5. Lyons, H. A., and R. Antonio. 1959. The sensitivity of the respiratory center in pregnancy and after the administration of progesterone. Trans. Assoc. Am. Physicians. 72: 173-180.

6. Skatrud, J. B., J. A. Dempsey, and D. G. Kaiser. 1978. Ventilatory response to medroxyprogesterone acetate in normal subjects: time course and mechanism. J. Appl. Physiol. 44: 939-944.

7. Lyons, H. A., and C. T. Huang. 1968. Therapeutic use of progesterone in alveolar hypoventilation associated with obesity. Am. J. Med. 44: 881-888.

8. Sutton, F. D., Jr., C. W. Zwillich, E. E. Creagh, D. J. Pierson, and J. V. Weil. 1975. Progesterone for outpatient treatment of Pickwickian syndrome. Ann. Intern. Med. 83: 476-479.

9. Kryger, M., R. E. McCullough, D. Collins, C. H. Scoggin, J. V. Weil, and R. F. Grover. 1978. Treatment of excessive polycythemia of high altitude with respiratory stimulant drugs. Am. Rev. Respir. Dis. 117: 455-464.

10. Tyler, J. M. 1960. The effect of progesterone on the respiration of patients with emphysema and hypercapnia. J. Clin. Invest. 39: 34-41.

11. Cullen, J. H., V. C. Brum, and W. U. Redit. 1959. The respiratory effects of progesterone in severe pulmonary emphysema. Am. J. Med. 27: 551-557.

12. Lyons, H. A. 1976. Centrally acting hormones and respiration. Pharmacol. Ther. 2: 743-751.

13. Sorli, J., A. Grassino, G. Lorange, and J. Milic-Emili. 1978. Control of breathing in patients with chronic obstructive lung disease. Clin. Sci. Mol. Med. 54: 295-304.

14. Morris, J. F., A. Koski, and L. C. Johnson. 1971. Spirometric standards for healthy nonsmoking adults. Am. Rev. Respir. Dis. 103: 57-67.

15. Ogilvie, C. M., R. E. Forster, W. S. Blakemore, and J. W. Morton. 1957. A standardized breath holding technique for the clinical measurement of the diffusing capacity of the lung for carbon monoxide. J. Clin. Invest. 36: 1-7.

16. Hyatt, R. E., I. R. Zimmerman, G. M. Peters, and W. J. Sullivan. 1970. Direct writeout of respiratory resistance. J. Appl. Physiol. 28: 675-678.

17. Dempsey, J. A., H. V. Forster, and G. A. doPico. 1974. Ventilatory acclimatization to moderate hypoxnia: role of spinal fluid $[\mathrm{H}+]$. J. Clin. Invest. 53: 1091-1100.

18. Matthews, A., and J. Howell. 1975. The rate of isometric inspiratory pressure development as a measure of responsiveness to carbon dioxide in man. Clin. Sci. Mol. Med. 49: $57-68$.

19. Read, D. J. C. 1967. A clinical method of assessing the ventilatory response to carbon dioxide. Australas. Ann. Med. 16: 20-32.

20. Ito, H., and D. N. Aviado. 1968. Prevention of pulmonary emphysema in rats by progesterone. J. Pharmacol. Exp. Ther. 161: 197-204.

21. Riley, R. L. 1954. The work of breathing and its relation to respiratory acidosis. Ann. Intern. Med. 41: 172.

22. Skatrud, J. B., J. A. Dempsey, and W. B. McHugh. 1979. Effect of acute and chronic alteration in afferent chemical input on sleep ventilation in man. Fed. Proc. 38: 1140 (Abstr.)

23. Altose, M. D., W. C. McCauley, S. G. Kelsen, and N. S. Cherniack. 1977. Effects of hypercapnia and inspiratory flow-resistive loading on respiratory activity in chronic airways obstruction. J. Clin. Invest. 59: 500-507.

24. Brodovsky, D. J., J. A. MacDonnell, and R. M. Cherniack. 1960. The respiratory response to carbon dioxide in health and in emphysema. J. Clin. Invest. 39: 724-729.

25. Maranetra, N., and M. C. F. Pain. 1974. Ventilatory drive and ventilatory response during rebreathing. Thorax. 29: $578-581$.

26. Lourenco, R. V., and J. M. Miranda. 1968. Drive and performance of the ventilatory apparatus in chronic obstructive lung disease. $N$. Engl. J. Med. 279: 53-59.

27. Wagner, R. D., D. R. Dantzker, R. Dueck, J. L. Clausen, and J. B. West. 1977. Ventilation perfusion inequality in chronic obstructive lung disease. J. Clin. Invest. 59: 203-216.

28. Gilbert, R., J. Keighley, and J. Auchincloss. 1965. Mechanisms of chronic carbon dioxide retention in patients with obstructive pulmonary disease. Am. J. Med. 38: 217-225.

29. Burrows, B., F. Saksena, and C. Diener. 1966. Carbon dioxide tension and ventilatory mechanics in chronic obstructive lung disease. Ann. Intern. Med. 65: 685-700.

30. Bradley, C. A., J. A. Fleetham, and N. R. Anthonisen. 1979. Ventilatory control in patients with hypoxemia due to obstructive lung disease. Am. Rev. Respir. Dis. 120: $21-29$. 